\title{
Estimating methane emissions from enteric fermentation for the UK greenhouse gas inventory
}

\author{
J. A. N. Mills ${ }^{1}$, L. A. Crompton ${ }^{1}$, A. Bannink ${ }^{2}$ and C. K. Reynolds ${ }^{1}$ \\ ${ }^{1}$ Animal Science Research Group, School of Agriculture, Policy and Development, University of Reading, Whiteknights, \\ PO Box 228, Reading RG6 6AR, UK and ${ }^{2}$ Animal Nutrition Group, Wageningen Institute of Animal Science Wageningen \\ University, Marijkeweg 40, 6709 PG, Wageningen, The Netherlands
}

Methane emissions from agriculture contribute approximately $38 \%$ of the UK's total methane output according to the UK national emissions inventory. The inventory relies on IPCC Tier 2 methodology ${ }^{(1)}$ for estimating methane from enteric fermentation by ruminant livestock, which are the major source of this gas. The Tier 2 approach adopts an emission factor $Y m$ (currently 6\%) expressed as a percentage of gross energy intake (GEI) for each animal. Given the growing emphasis on conforming to international emissions targets, this research set out to examine whether this emission factor provides an adequate estimate of methane output from cattle in the UK.

Measurements of energy balance were collected into a database for meta-analysis of effects of diet parameters on methane emissions from growing and lactating cattle. An existing dataset from the University of Reading was updated and expanded using additional in house data and data from the USA and the Netherlands. In total, the database included 1335 records of methane emission, along with varying amounts of information on diet formulation, diet composition and the cows used in each experiment. Firstly, an analysis was conducted, with appropriate adjustments for trial effects, to determine the relationship between $Y m$ and dietary variables. Data were integrated and corrected for variation due to location and experiment using Mixed Models procedures of SAS (SAS Institute Inc., Cary, NC) and linear regression models ${ }^{\left({ }^{2}\right)}$. Secondly, based on earlier observations ${ }^{\left({ }^{3}\right)}$, a non-linear Mitscherlich model was fitted to the data as an alternative approach to estimate methane emission. The Mitscherlich model was used to describe the relationship between dry matter intake (DMI) and methane output as follows:

$$
\text { Methane }(\mathrm{MJ} / \mathrm{d})=a-(a+b) \mathrm{e}^{-\mathrm{cDMI}}
$$

where $a$ and $b$ are the maximum and minimum values of methane, respectively, and $c$ is a shape parameter determining the change with increasing DMI.

The analysis showed that $Y m$ varied according to DMI as shown by the linear model in Fig. 1, with a decline in $Y m$ as DMI increased although the correlation displayed significant variation $\left(r^{2}=0.41\right)$. For the relationship between DMI and methane emission $(\mathrm{MJ} / \mathrm{d})(\mathrm{not}$ shown), the Mitscherlich model described the data well with an $r^{2}$ of 0.91 .

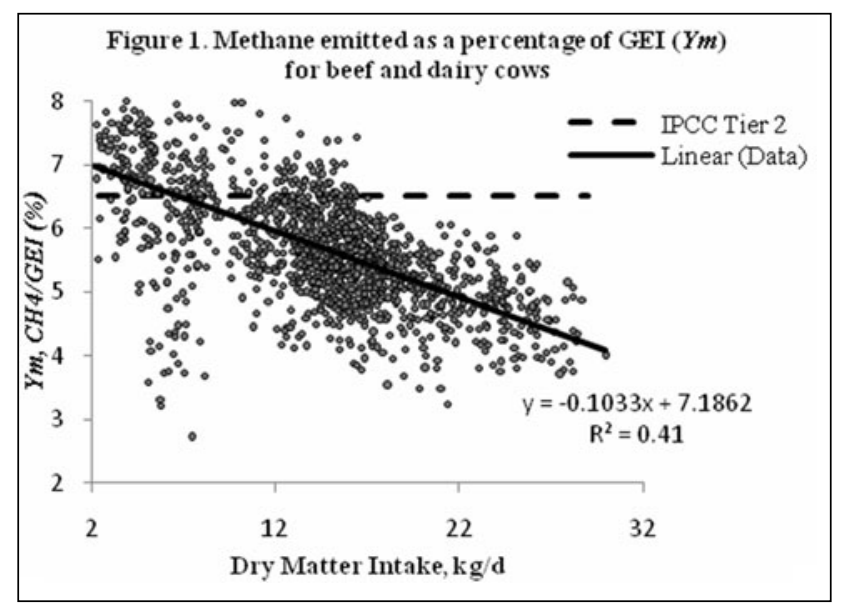

According to this analysis, the adoption of a static emission factor $(\mathrm{Ym})$ fails to adequately describe the observed relationship between the proportion of feed energy lost as methane across a wide range of feed intakes. This error will inevitably lead to inaccuracy in the prediction of methane emissions per animal when using the Tier 2 methodology. However, rather than suggesting a refinement of $Y m$ that reflects the increase in efficiency as intake rises (such as that shown by the linear model fitted in Fig. 1), it seems more appropriate to adopt a direct approach to estimating emissions from feed intake as defined by the non-linear Mitscherlich model.

1. 2006 IPCC Guidelines for National Greenhouse Gas Inventories.

2. St-Pierre NR (2001) J Dairy Sci 84, 741-755.

3. Mills JAN, Kebreab E, Yates CM et al. (2003) J Anim Sci 81, 3141-3150. 